treatment, and follow up for the condition in question, with one senior person locally responsible for coordinating all screening activities. Thirdly, an authoritative national body should be established to monitor and evaluate new proposals for screening and ensure that its recommendations are considered before current practices are changed substantially or new test procedures introduced.

The principles and criteria to be used by such a body are well established. ${ }^{11}$ In brief, they are that when considering any new proposal account should be taken of all relevant scientific evidence, the availability of effective treatment, the importance of the condition, and the financial implications.

The resource consequences of screening are important. When resources in the health services are scarce and their use is under careful scrutiny, ineffective or inappropriate screening must be avoided. Screening is not necessarily benign and, with the proliferation of new technology and techniques, never has it been more important to maintain stringent criteria for any proposed programme. As Archie Cochrane and I wrote over 20 years ago, there is an ethical difference between everyday medical practice and screening. If patients ask doctors for help then doctors do the best they can. They are not responsible for defects in medical knowledge. "If, however, the practitioner initiates screening procedures he is in a very different situation. He should, in our view, have conclusive evidence that screening can alter the natural history of the disease in a significant proportion of those screened." 1112 Only if screening is carried out efficiently and humanely, leads to an improved outcome in those concerned, and is properly monitored and evaluated should it be contemplated.

WALTER W HOLLAND Professor

Department of Public Health Medicine,

St Thomas's Hospital,

London SE1 7EH

1 Clarke A, Parsons EP. Screening, ethics, and the law. BMY 1993;306:209.

2 Leese GP, Ahmed S, Newton RW, Jung RT, Ellingford A, Baines P, et al. Use of mobile screening unit for diabetic retinopathy in rural and urban areas. $B M$ f $^{1993 ; 306: 187-9 .}$

3 Parker L, Craft AW, Dale G, Bell S, Cole M, McGill AC, et al. Screening for neuroblastoma in the north of England. BMF 1992;305:1260-3.

4 Wiggens $S$, Whyte $P$, Huggins M, Adam S, Theilmann J, Bloch M, et al. The psychological consequences of predictive testing for Huntington's disease. N Engl f Med 1992;327:1401-5.

5 Morrell DC. Role of research in development of organisation and structure of general practice. BMF 1991;302:1313-6.

6 Stoate H. Can health screening damage your health? I R Coll Gen Pract 1989;39:193-5.

7 Babaian RJ, Miyashita H, Evans RB, Ramirez EI. The distribution of prostate specific antigen in men without clinical or pathological evidence of prostate cancer: relationship to gland volume and age. $I$ Urol 1992;147:837-40.

8 Office of Population Censuses and Surveys. Cancer statistics registrations 1986. London: HMSO 1991. (Series MBI No 19.)

9 Office of Population Censuses and Surveys. DH No 17

10 Advisory Council on Science and Technology. $A$ report on medical research and health. London: HMSO, 1993.

11 Wilson JMG, Jungner G. Principles and practice of screening for disease. Geneva: World Health Organisation, 1968.

12 Cochrane AL, Holland WW. Validation of screening procedures. Br Med Bull 1971;27(1):3-8.

\title{
Health care reform
}

\section{The difficulties of controlling spending at the macro level while promoting efficiency at the micro level}

Health care systems seem to come in all shapes and sizes, but at least in developed countries several common models can be identified. As a recent study from the Organisation for Economic Cooperation and Development (OECD) has shown, three models are particularly prevalent. ${ }^{1}$

The public integrated model involves financing health services through taxation along the lines of Britain's NHS. This model is described as integrated because public financing is combined with public ownership of hospitals and salaried employment of doctors. Hospitals are funded through global budgets, and services are usually provided free at the point of use to patients.

The public contract model involves financing health services through compulsory insurance along the lines of the German health system. ${ }^{2}$ Sickness funds act as health insurance organisations, which are responsible for ensuring that services are available to their subscribers. These services are delivered by independent providers under contract to the sickness funds.

The public reimbursement model also involves compulsory insurance financing of health services through sickness funds. In contrast to the public contract model, there is no connection between the sickness funds and providers. Providers deliver care to patients, who are reimbursed by the sickness funds for out of pocket, fee for service payments to independent providers. Both the French and Belgian health systems have traditionally been based on this model.

In reality, each country's health care system includes elements of more than one model. For example, in Britain the financing of primary care services, with its emphasis on independent contractor status for family practitioners, contains many of the features of the public contract model. It is also the case that health care reforms are producing changes in the mixture of arrangements found in different countries. Britain again exemplifies this, with its shift from the public integrated model to the public contract model through the separation of purchaser and provider roles and the introduction of a managed market.

Whatever the preferred approach, policy makers in all countries have shared a concern to contain the growth of spending on health services. In this respect, they have been remarkably successful. Seven members of the OECD reduced sharply the rate of growth of their health expenditure in the 1980 s compared with the 1970 s. Cost containment was particularly effective in the integrated systems of Britain, the Republic of Ireland, and Spain. Those countries relying on the reimbursement model-Belgium and France-had the greatest difficulty in containing costs, while the contract based systems of Germany and the Netherlands fell in the middle.

In all seven countries, public financing remained the favoured method of paying for health care. Indeed, two countries-the Netherlands and Spain-took steps to extend the scope of public financing to ensure universal coverage for their populations. Despite calls for privatisation and the imposition of cost sharing arrangements, no country made a significant move in this direction. Instead, priority was given to supply side measures, like the imposition of global budgets for hospitals. And as the 1980 s wore on, policy makers turned their attention to reforms involving the introduction of competitive principles. This was prompted by a belief that these reforms would offer stronger incentives for the efficient use of resources and would motivate providers to be more responsive to users. 
Britain and the Netherlands have been at the forefront of these developments, followed closely by Germany. In the Netherlands the Dekker Report of 1988 has led to the introduction of competition between both insurers and providers. The aim is to establish a system in which patients may choose between insurers who in turn will contract selectively with providers. These changes are being implemented over a period of years and it will take some time before they come fully into effect.

Viewed in the Dutch context, the pace of reform in Britain seems reckless in the extreme. An alternative interpretation is that the existence of a majority government has provided Margaret Thatcher and now John Major with an ability to act, which their European counterparts observe with envy. From this position, British policy makers have been able to act decisively to tackle weaknesses in the financing and delivery of health services, and their experience is being followed closely throughout the developed world. In this respect, the NHS has become a laboratory for other countries, acting as a test bed for the grafting on of competition to a managed system.

The unanswered question is, will the experiment prove a success? We don't yet know. As the OECD's analysis is right to point out, although there are some encouraging signs, there is as yet insufficient experience and evidence on which to make a firm judgment.

Even more important, whatever the long term benefits of managed markets, there may well be a price to pay in terms of reduced access to care and greater inequity in service delivery. These are the inevitable trade offs involved in designing health care systems. There are also limits to which supply side reforms can be expected to compensate for underfunding. ${ }^{3}$ To this extent, the cost containment policies of the 1980s may have tackled one set of problems only to have caused others. The puzzle is how to combine the control of expenditure at the macro level with real incentives for efficiency at the micro level. The country that is able to solve this puzzle will indeed be the envy of the world

PROFESSOR CHRIS HAM Director

Health Services Management Centre,

University of Birmingham,

Birmingham B15 2RT

1 Organisation for Economic Development and Cooperation. The reform of health care: a comparative analysis of seven OECD countries. Paris, OECD: 1992.

2 Von Stillfried D, Arnold M. What's happening to health care in Germany? BMF 1993;306:1017-8. 3 Ham C. How go the NHS reforms? BMf 1993;306:77-8.

\section{Open access upper gastrointestinal endoscopy}

\section{Popular, but is it right?}

Demand for open access endoscopy, the investigation of dyspeptic symptoms in patients directly referred from general practitioners to endoscopy clinics without prior hospital screening, ${ }^{1}$ is growing. Current estimates suggest that such services are available in about half of Britain. ${ }^{2}$ Consultant gastroenterologists being appointed around the country are charged with setting up these services, and the investigation is popular with general practitioners, particularly fundholders. Its economic appeal is obvious: bypassing outpatient departments probably cuts the cost of referral by half. ${ }^{3}$

But is it the right thing to do? Our understanding of the pathogenesis of dyspepsia, one of the commonest symptoms, is poor, and our management mainly empirical. ${ }^{4}$ Clinical assessment and some form of investigation are mandatory in many patients, but investigation reveals only relatively trivial underlying disease in most. ${ }^{4}$ Attempts have been made with computer based questionnaires, ultrasonography, serological testing for Helicobacter pylori, studies of gastric acid secretion, acid perfusion tests, $\mathrm{pH}$ monitoring, oesophageal manometry, and gastric emptying measurements to separate out subgroups, but mostly to no avail. Endoscopy is undoubtedly the most sensitive tool we have to investigate the upper gastrointestinal tract ${ }^{5-7}$ : it is more accurate than even a double contrast barium meal examination and permits direct visualisation and biopsy, confirming inflammatory changes, neoplasms, or $H$ pylori infection. But even so it is not necessarily the right first line investigation for all patients, given its expense, risks, and inconvenience.

Studies have suggested various benefits for the investigation. ${ }^{89}$ In the largest published series, Gear and Wilkinson reported that endoscopy progressively replaced barium meal studies and was popular with general practitioners, which led to more referrals. ${ }^{10}$ The case has been made for using this technique primarily to identify early gastric cancer, ${ }^{11}$ and its use to exclude cancer in dyspeptic patients presenting over the age of 40 is easy to justify. ${ }^{411}$
But others have been less enthusiastic and found its benefits less clear cut. Holdstock et al did not find that more ulcers and gastric neoplasms were detected, and attempts to improve diagnostic accuracy by using a scoring system had only limited success. ${ }^{12} 13$

No evidence currently exists for initially investigating all dyspeptic patients endoscopically. The widespread introduction of endoscopy before proper evaluation would therefore seem to be a classic example of how market forces distort patterns of medical care. Deciding on the proper role of this procedure would seem vital. Other screening tests also deserve evaluation to decide whether they are preferable to endoscopy in the initial management of patients with dyspepsia. ${ }^{6}$

R V HEATLEY

Department of Clinical Medicine Consultant physician

St James's University Hospital,

Leeds LS9 7TF

1 Jones R. Open access endoscopy. $B M \mathcal{F}$ 1985;291:424-6.

2 Bramble MG. Open access endoscopy-a nationwide survey of current practice. Gut 1992;33 282-5.

3 Lancaster Smith $M$, Gough $K$, Wells N, Miocevich $M$. An economic analysis of ranitidine versus cimetidine in the prevention of duodenal ulcer recurrence. Br $\mathcal{Y}$ Med Economics 1992;2:25-36.

Heatley RV, Rathbone BJ. Dyspepsia: a dilemma for doctors? Lancet 1987;i:779-81.

5 Talley NJ, Phillips SF. Non-ulcer dyspepsia: potential causes and pathophysiology. Ann Intern Med 1988;108:865-79.

6 Sobala GM, Crabtree JE, Pentith JA, Rathbone BJ, Shallcross TM, Wyatt JI, et al. Screening dyspepsia by serology to Helicobacter pylori. Lancet 1991;338:94-6.

Colin-Jones DG. Endoscopy or radiology for upper gastrointestinal symptoms. Lancet 1986; 1022-3.

8 Kerrigan DD, Brown SR, Hutchinson GH. Open access gastroscopy: too much to swallow? $B M$ 1990;300:374-6.

Hungin AS. Use of an open access gastroscopy service by a general practice. Findings and subsequent referral rate. $f R$ Coll Gen Pract 1987;37:170-1.

10 Gear MWL, Wilkinson SP. Open access upper alimentary endoscopy. Br $\mathcal{F}$ Hosp Med 1989;41: 438-44.

11 Hallissey MT, Allum WH, Jewkes AJ, Ellis DJ, Fielding JWL. Early detection of gastric cancer. BMF 1990;301:513-5.

12 Holdstock G, Wiseman $M$, Loehry CA. Open access service for general practitioners. BMF 1979;i:457-9.

13 Mann J, Holdstock G, Harman M, Machin D, Loehry CA. Scoring system to improve cost effectiveness of open access endoscopy. BMf 1983;287:937-40. 